\title{
MITRAL VALVOTOMY IN RELATION TO PREGNANCY
}

BY

\author{
D. McC. BOYLE, M. J. O'DONNELL, AND J. F. PANTRIDGE \\ From the Royal Victoria Hospital and Royal Maternity Hospital, Belfast
}

Received July 12, 1963

Conflicting views have been expressed regarding the advisability of mitral valvotomy in pregnancy. Little attention has been paid to the effect of pregnancy on the deterioration in cardiac status subsequent to mitral valvotomy. This study has been undertaken in an effort to clarify these two issues.

Before June 1963, 903 patients under the care of one of us (J.F.P.) had mitral valvotomy. Of these, 41 had the operation during pregnancy. Among the remainder were 58 patients who became pregnant subsequent to the operation.

\section{Mitral Valvotomy During Pregnancy}

In the first part of the study the 41 patients who had the operation during pregnancy have been compared with a similar number of women who had the operation when not pregnant. Each patient in the pregnancy group was matched with a control patient in regard to criteria shown in Table I. These criteria ensure that the members of the control group before operation resemble those of the pregnancy group before conception. Differences in the two groups are said to be significant when $\mathrm{p}<0.05$.

A previous paper (Marshall and Pantridge, 1957) reviewed 18 patients who are included in the present study.

Table II gives details of the patients who had mitral valvotomy during pregnancy. Their ages varied from 25-39 years, and $21(51 \%)$ were aged over 30 years. Disability before pregnancy (New York Heart Association, 1939) had been Grade I or II in $17(41.5 \%)$, Grade III in $17(41.5 \%)$,

\section{TABLE I}

Criteria used to Choose Control Patients for Comparison with Patients having Mitral Valvotomy during PREGNANCY

1. Sex

2. Age at time of operation (a) 21-30 years

(b) $31-40$ years

3. Cardiac rhythm before operation

4. Clinical evidence of mitral incompetence, or aortic valve disease associated with cardiographic or $\mathrm{x}$-ray evidence of left ventricular hypertrophy before operation

5. Cardiographic evidence of right ventricular hypertrophy (Milnor, 1957)

6. Functional disability (graded by criteria of New York Heart Association, 1939, but combining Grades I and II) comparing control patients before valvotomy with pregnant patients before conception

7. When more than one patient is available as a control, that patient whose operation occurred nearest in time to that of the pregnant patient was used 
TABLE II

Data Relating to Patients having Mitral Valvotomy during Pregnancy

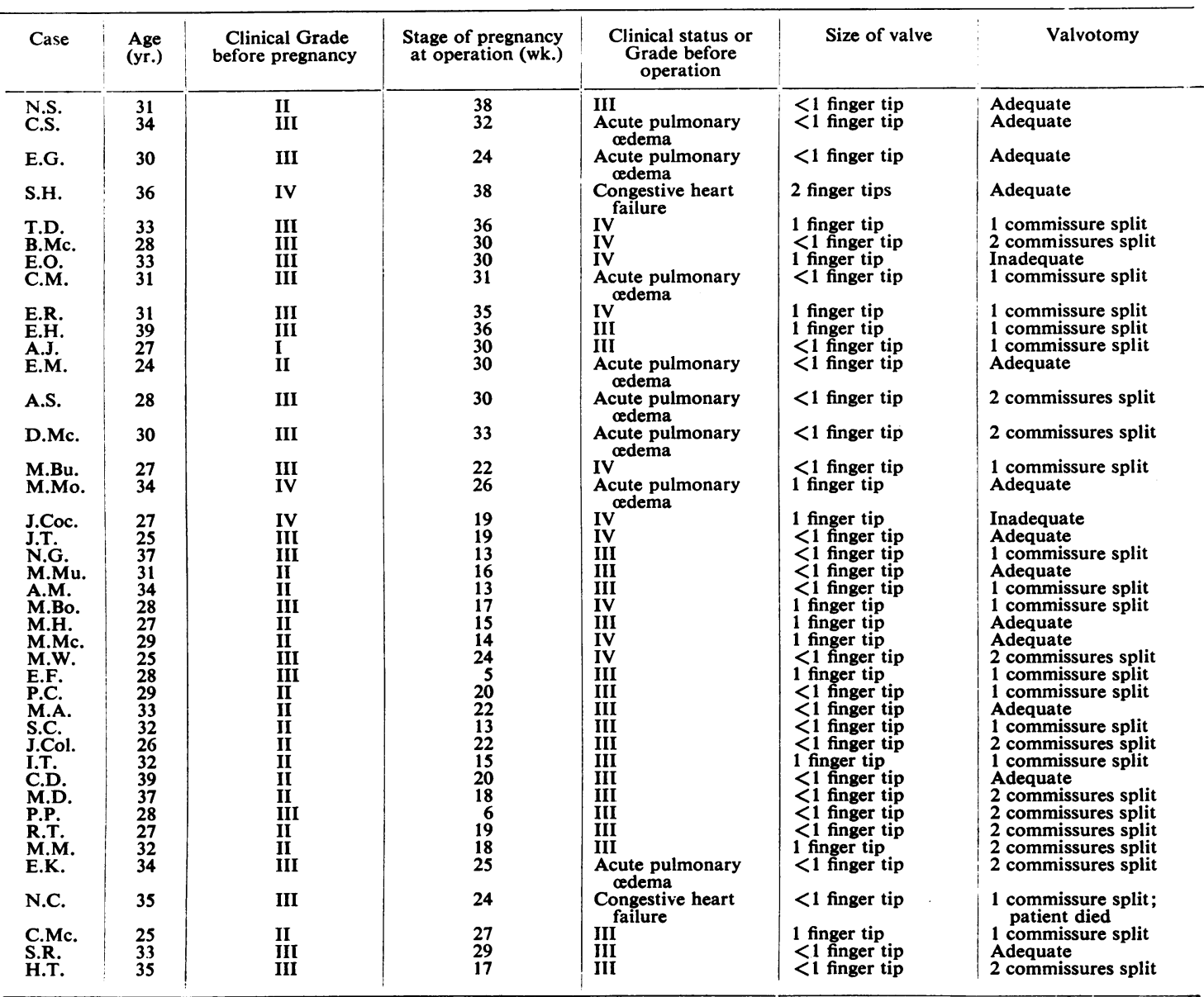

TABLE III

Mitral Valvotomy during Pregnancy: Pregnant Patients in Clinical Grade I or II after Operation COMPARED WITH NON-PREGNANT CONTROLS

\begin{tabular}{|c|c|c|c|c|c|c|}
\hline \multirow{2}{*}{$\begin{array}{l}\text { Time of } \\
\text { follow-up } \\
\text { (yr.) }\end{array}$} & \multicolumn{2}{|c|}{ Pregnancy group } & \multicolumn{2}{|c|}{ Control group } & \multirow{2}{*}{ Difference } & \multirow{2}{*}{$\begin{array}{c}\text { S.E. } \\
\text { difference }\end{array}$} \\
\hline & $\%$ Grade I or II & S.E. & $\%$ Grade I or II & S.E. & & \\
\hline $\begin{array}{c}6 / 12 \\
1 \\
2 \\
3 \\
4 \\
5 \\
6 \\
7 \\
8 \\
9\end{array}$ & $\begin{array}{l}95 \cdot 1 \\
95 \cdot 1 \\
95 \cdot 1 \\
83 \cdot 6 \\
77 \cdot 4 \\
74 \cdot 0 \\
74 \cdot 0 \\
68 \cdot 3 \\
67 \cdot 5 \\
50 \cdot 6\end{array}$ & $\begin{array}{r}3 \cdot 36 \\
3 \cdot 36 \\
3 \cdot 36 \\
6 \cdot 15 \\
7 \cdot 01 \\
7 \cdot 51 \\
7 \cdot 51 \\
8 \cdot 83 \\
9 \cdot 17 \\
16 \cdot 16\end{array}$ & $\begin{array}{r}100 \cdot 0 \\
97 \cdot 6 \\
97.6 \\
88.6 \\
82.1 \\
82.1 \\
77.7 \\
77.7 \\
77.7 \\
58.3\end{array}$ & $\begin{array}{l}0 \\
2.39 \\
2.39 \\
5.40 \\
6.66 \\
6.66 \\
7.63 \\
7.63 \\
7.63 \\
18.07\end{array}$ & $\begin{array}{r}4 \cdot 9 \\
2 \cdot 5 \\
2.5 \\
5.0 \\
4.7 \\
8 \cdot 1 \\
3 \cdot 7 \\
9 \cdot 4 \\
10 \cdot 2 \\
7 \cdot 7\end{array}$ & $\begin{array}{c}3 \cdot 36 \\
4 \cdot 12 \\
4 \cdot 12 \\
8 \cdot 85 \\
9 \cdot 66 \\
10 \cdot 0 \\
10 \cdot 7 \\
11.7 \\
11.9 \\
24 \cdot 2\end{array}$ \\
\hline
\end{tabular}


and Grade IV in $7(17 \%)$. However, all patients showed severe disability before operation, and 8 $(20 \%)$ had been in acute pulmonary œdema, and $2(5 \%)$ had had signs of congestive heart failure.

No patients had mitral incompetence or aortic valve disease producing cardiographic or $\mathrm{x}$-ray evidence of left ventricular hypertrophy. Atrial fibrillation was present in 4 patients $(10 \%)$; cardiographic evidence of right ventricular hypertrophy was present in $9(22 \%)$. In one instance cerebral embolism had occurred before pregnancy began and in another left hemiplegia developed at operation. In the control group, 2 patients $(5 \%)$ had had previous cerebral emboli but no embolization occurred at the time of operation.

Among the patients with mitral valvotomy during pregnancy, $25(61 \%)$ had had a total of 69 previous pregnancies, and in the control group $19(46 \%)$ had had 33 pregnancies before operation. A difference is expected since many of the control group were unmarried. The stage of pregnancy at which mitral valvotomy was performed varied from 5 to 38 weeks. In 14 patients $(34 \%)$ the stage of pregnancy was greater than 28 weeks.

Operative findings in the two groups were similar. The mitral valve would not admit the tip of the surgeon's index finger in $27(66 \%)$ of the pregnant women and in $30(73 \%)$ of the control patients. In $3(7 \%)$ of the pregnant women the surgeons felt a regurgitant jet at operation, and this also happened in $3(7 \%)$ of the controls. In no case was the jet considered more than slight.

The findings at follow-up examination, which varied from 6 months to 10 years after operation, have been summarized in Table III which shows the percentage of patients remaining in clinical Grade I or II, calculated using the actuarial method (Berkson and Gage, 1950).

There was one maternal death in the pregnancy group $(2 \%)$. This patient, N.C., a primigravida aged 35, was admitted to hospital in congestive heart failure complicated by chest infection. She failed to respond to intensive medical therapy, and when mitral valvotomy was performed the patient was moribund. Tight stenosis was found, and the lateral commissure was split to the valve ring. She died 48 hours after operation.

Fœtal or neonatal death occurred in 7 patients $(17 \%)$, and premature birth may have resulted from the operation in 6 patients $(15 \%)$.

There were no deaths in the follow-up period either in the pregnant group or in the control group. Table III shows the percentage of patients in each group who were in clinical Grade I or II at times of follow-up. One year after operation 95 per cent of the pregnant group were in Grade I or II compared with 98 per cent of the control group, and at six years after operation 74 per cent of the pregnant group were in Grade I or II compared with 78 per cent of the controls. These figures include the patient who died at operation. At no time is the difference between the two groups significant. During the time of follow-up $7(17 \%)$ patients of the pregnancy group and $5(12 \%)$ of the control group have needed a second operation for valvotomy.

Since their operation 13 patients $(32 \%)$ whose valvotomy was performed during pregnancy have had 24 further pregnancies. In the control group $9(22 \%)$ have had 10 pregnancies after operation.

Maternal mortality in rheumatic heart disease has fallen as antenatal care has improved. Most patients can tolerate pregnancy if they are willing to adhere to a strict medical régime in which the most important factor is rest. Alternatives to strict conservative treatment are therapeutic abortion early in pregnancy, and mitral valvotomy in cases of mitral stenosis. The indications for mitral valvotomy in pregnancy are uncertain. Burwell (1954) considers that valvotomy is "reserved for cases in which management has failed and termination is inadvisable." Mulcahy (1954) suggests that "valvotomy has an especially important place in reducing disability and invalidism" during pregnancy. Brigden (1961) writes "if it is a fact that there are indications for mitral valvotomy it makes little difference whether the patient is pregnant or not."

The arguments used by those who advise against mitral valvotomy during pregnancy are that the diagnosis of pure mitral stenosis is less accurate in these patients, and that the hæmodynamic state during pregnancy is such that the operative risk is greater than the risk of continuing the pregnancy under strict medical supervision (Gilchrist, 1963).

In the present series, no patient was found to have significant mitral incompetence at operation 
and the number with minor incompetence was similar to that in the control group. Very tight mitral stenosis occurred with about equal frequency in both groups.

The one maternal death occurred in a patient with congestive heart failure who had not responded to medical treatment, and whose condition was deteriorating rapidly. Mitral valvotomy earlier in pregnancy might have saved her life. We have found that in non-pregnant patients with congestive heart failure not responding to medical treatment operative mortality is very high-17 per cent (Boyle, 1960).

The present study indicates that the risk of mitral valvotomy during pregnancy should not be greater than operation in non-pregnant women. It also indicates that diagnostic difficulties do not preclude mitral valvotomy in pregnancy. Finally, a follow-up has shown that the results of the operation during pregnancy are as good as those of the operation in non-pregnant women.

TABLE IV

Criteria used to choose Control. Patients for Comparison with Patients who became Pregnant Subsequent to Mitral VALVOTOMY

1. Sex

2. Age (yr.) before mitral valvotomy (a) $0-20$; (b) 21-30; (c) 31-40

3. Functional disability before mitral valvotomy (New York Heart Association, 1939)

4. Cardiac rhythm before mitral valvotomy

5. Clinical evidence of mitral incompetence or aortic valve disease associated with cardiographic or $\mathrm{x}$-ray evidence of left ventricular hypertrophy

6. Cardiographic evidence of right ventricular hypertrophy (Milnor, 1957) before valvotomy

7. Presence of calcification in valve cusps as recorded by surgeon

8. Degree of split obtained by surgeon (a) nil or inadequate; $(b)$ adequate but less than $(c) ;(c)$ at least one commissure split to valve ring

9. Functional disability at follow-up corresponding to that before pregnancy

10. Cardiac rhythm at follow-up corresponding to that before pregnancy

11. Clinical evidence of mitral incompetence or aortic valve disease associated with cardiographic or $\mathrm{x}$-ray evidence of left ventricular hypertrophy at follow-up corresponding to that before pregnancy

12. When more than one patient is available as a control, that patient whose operation occurred nearest in time to that of pregnant patient was used

\section{Pregnancy Subsequent to Mitral Valvotomy}

In the second part of the study the clinical status of the 58 patients who became pregnant after mitral valvotomy was compared with that of a control group of women who did not become pregnant after operation. This control group was matched with the pregnancy group using the criteria shown in Table IV. The two groups were matched so as to be similar at the time immediately before mitral valvotomy. They were also matched so that the clinical status of a patient immediately before pregnancy was similar to that of the control.

The clinical status at the follow-up examinations after pregnancy has been recorded and compared with the findings at the equivalent follow-up periods for the control patients (Tables V and VI). These have been expressed using the actuarial method in terms of the percentage of patients who had deteriorated from their pre-pregnancy status. Differences between the two groups were said to be significant when $\mathrm{p}<0.05$.

Each group contained 3 patients $(5 \%)$ aged under 20 years, 35 patients $(60 \%)$ aged $21-30$ years, and 20 patients $(35 \%)$ aged $31-40$ years at the time of mitral valvotomy. The interval between the operation and pregnancy varied from one to seven years, the average interval being 3.4 years. Electrocardiographic evidence of right ventricular hypertrophy was present in $12(21 \%)$ patients. At the examination before pregnancy 50 patients $(86 \%)$ were in clinical Grade I, $7(12 \%)$ in Grade II, and $1(2 \%)$ in Grade III. Atrial fibrillation was present in $6(10 \%)$. In no case was there clinical evidence of mitral incompetence or aortic valve disease associated with $\mathrm{x}$-ray or cardiographic evidence of left ventricular hypertrophy. Following pregnancy 1 patient $(2 \%)$ died and $5(8 \%)$ have required a second operation. None died during pregnancy. In the control series there have been no deaths and $4(6 \%)$ had second operations. 
TABLE V

Pregnancy Subsequent to Mitral Valvotomy: Deterioration* of Pregnant Patients Compared with NON-PREGNANT CONTROLS

\begin{tabular}{|c|c|c|c|c|c|c|}
\hline \multirow{2}{*}{$\begin{array}{l}\text { Time of } \\
\text { follow-up } \\
\text { (yr.) }\end{array}$} & \multicolumn{2}{|c|}{ Pregnancy group } & \multicolumn{2}{|c|}{ Control group } & \multirow{2}{*}{ Difference } & \multirow{2}{*}{$\begin{array}{l}\text { S.E. of } \\
\text { difference }\end{array}$} \\
\hline & $\%$ deteriorated & S.E. & $\%$ deteriorated & S.E. & & \\
\hline $\begin{array}{c}6 / 12 \\
1 \\
2 \\
3 \\
4 \\
5\end{array}$ & $\begin{array}{r}8.6 \\
14.3 \\
21 \cdot 3 \\
27.5 \\
35.8 \\
35.8\end{array}$ & $\begin{array}{l}3 \cdot 55 \\
4 \cdot 59 \\
5 \cdot 47 \\
6 \cdot 75 \\
8 \cdot 12 \\
8 \cdot 12\end{array}$ & $\begin{array}{c}0 \\
5 \cdot 6 \\
14 \cdot 6 \\
17.4 \\
26.9 \\
37 \cdot 5\end{array}$ & $\begin{array}{l}0 \\
3 \cdot 14 \\
5 \cdot 13 \\
5 \cdot 66 \\
7 \cdot 53 \\
9 \cdot 10\end{array}$ & $\begin{array}{r}8 \cdot 6 \\
8 \cdot 7 \\
6 \cdot 7 \\
10 \cdot 1 \\
7.9 \\
1 \cdot 7\end{array}$ & $\begin{array}{r}3 \cdot 55 \\
5 \cdot 57 \\
7 \cdot 70 \\
8 \cdot 81 \\
11 \cdot 07 \\
12 \cdot 19\end{array}$ \\
\hline
\end{tabular}

*Deterioration is said to have occurred if patient is down-graded at least two functional grades, or dies.

Table $\mathrm{V}$ shows the findings at follow-up when deterioration is defined as that producing a downgrading of at least two functional grades, or death. Six months after pregnancy 9 per cent of patients had deteriorated and the corresponding figure for the control group is nil-a significant difference. Table VI shows the findings when less strict criteria of deterioration are observed. In this, deterioration was held to occur if the patient was down-graded at least one functional grade, or died. At six months, 24 per cent had deteriorated compared with 3 per cent of the controls. At one year after pregnancy 35 per cent had deteriorated compared with 20 per cent of the control group. These differences are significant.

Previous studies (Gorenberg and Chesley, 1958; Miller and Metcalfe, 1956; Maynard and Grover, 1960) on the effect of pregnancy on the ultimate progress in chronic rheumatic heart disease suggests that deterioration is not accelerated. These studies differ from the present one in that the patients had not had mitral valvotomy and that their clinical disability before pregnancy was greater. This optimistic view is challenged. Donzelot, Heim de Balsac, and David (1958) found that one-third of a group of patients showed deterioration one year after pregnancy and that two-thirds of them had deteriorated five years after pregnancy. These figures are similar to those of Table IV of the present study where 35 per cent had deteriorated at one year and 61 per cent at five years. They conclude that the full effect of pregnancy in chronic rheumatic heart disease cannot be assessed until several years after the event.

Baker and Hancock (1960) found that out of 21 patients who became pregnant following mitral valvotomy $10(48 \%)$ showed clinical deterioration after the pregnancy. In the present study, reviews six months and one year after pregnancy indicate that pregnancy subsequent to mitral valvotomy increases the chance of deterioration in cardiac status. The number of patients available

TABLE VI

Pregnancy Subsequent to Mitral Valvotomy: Deterioration* of Pregnant Patients Compared with NON-PREGNANT CONTROLS

\begin{tabular}{|c|c|c|c|c|c|c|}
\hline \multirow{2}{*}{$\begin{array}{c}\text { Time of } \\
\text { follow-up } \\
\text { (yr.) }\end{array}$} & \multicolumn{2}{|c|}{ Pregnancy group } & \multicolumn{2}{|c|}{ Control group } & \multirow{2}{*}{ Difference } & \multirow{2}{*}{$\begin{array}{l}\text { S.E. of } \\
\text { difference }\end{array}$} \\
\hline & $\%$ deteriorated & S.E. & $\%$ deteriorated & S.E. & & \\
\hline $\begin{array}{c}6 / 12 \\
1 \\
2 \\
3 \\
4 \\
5\end{array}$ & $\begin{array}{l}22 \cdot 4 \\
35 \cdot 5 \\
44 \cdot 5 \\
56 \cdot 9 \\
61 \cdot 8 \\
70 \cdot 2\end{array}$ & $\begin{array}{l}5 \cdot 48 \\
6 \cdot 41 \\
6 \cdot 88 \\
7 \cdot 51 \\
8 \cdot 06 \\
9 \cdot 78\end{array}$ & $\begin{array}{r}3 \cdot 4 \\
18 \cdot 4 \\
34 \cdot 5 \\
50 \cdot 5 \\
57 \cdot 4 \\
62 \cdot 1\end{array}$ & $\begin{array}{l}2 \cdot 40 \\
5 \cdot 28 \\
6 \cdot 85 \\
7 \cdot 70 \\
8 \cdot 00 \\
8 \cdot 40\end{array}$ & $\begin{array}{r}19 \cdot 0 \\
17 \cdot 1 \\
10.0 \\
6 \cdot 4 \\
4 \cdot 4 \\
8 \cdot 1\end{array}$ & $\begin{array}{r}5 \cdot 98 \\
8 \cdot 30 \\
9 \cdot 71 \\
10 \cdot 72 \\
11 \cdot 36 \\
12 \cdot 36\end{array}$ \\
\hline
\end{tabular}

*Deterioration is said to have occurred if patient is down-graded at least one functional grade, or dies. 
for comparision between the two groups at later follow-ups was small. Since many patients are anxious to become pregnant after mitral valvotomy it is of some importance to know what effect pregnancy may have on the ultimate prognosis. Further studies with larger groups of patients are needed.

\section{SUMMARY}

The results of mitral valvotomy in 41 pregnant patients are reported. There was one maternal death. Comparison of the results with those in a similar group of women who had mitral valvotomy when not pregnant showed no significant difference between the two groups. It is suggested that the indications for mitral valvotomy during pregnancy are the same as for those who are not pregnant.

A further 58 patients who became pregnant after mitral valvotomy have been compared with a similar group of women who did not become pregnant subsequent to operation. This comparison suggests that pregnancy subsequent to mitral valvotomy increases the chances of deterioration in cardiac status.

\section{REFERENCES}

Baker, C., and Hancock, W. E. (1960). Deterioration after mitral valvotomy. Brit. Heart J., $22,281$.

Berkson, J., and Gage, R. P. (1950). Calculation of survival rates for cancer. Proc. Mayo Clin., $25,270$.

Boyle, D. (1960). Medical aspects of mitral valvotomy. M.D. Thesis, Queen's University of Belfast.

Brigden, W. (1961). In Panel discussion on rheumatic heart disease: diagnosis and treatment. Jap. Circulat.J. (En.), 25, 761 .

Burwell, C. S. (1954). The management of heart disease in pregnant women. Bull. Johns Hopk. Hosp., 95, 130.

Donzelot, E., Heim de Balsac, R., and David, A. (1958). Aggravation of mitral heart disease following pregnancy. A statistical study of 233 cases. Amer. J. Cardiol., $1,51$.

Gilchrist, A. R. (1963). Cardiological problems in younger women, including those of pregnancy and the puerperium. Brit. med. J., 1, 209.

Gorenberg, H., and Chesley, L. C. (1958). Rheumatic heart disease in pregnancy: the remote prognosis in patients with "functionally severe" disease. Ann. intern. Med., 49, 278.

Marshall, R. J., and Pantridge, J. F. (1957). Mitral valvotomy during pregnancy. Brit. med. J., 1, 1097.

Maynard, E. P., Jr., and Grover, V. (1960). The effect of childbearing on the course of rheumatic heart disease: A 25-year study. Ann. intern. Med., 52, 163.

Miller, M. M., and Metcalfe, J. (1956). Effect of pregnancy on the course of heart disease. Re-evaluation of 106 cardiac patients 3 to 5 years after pregnancy. Circulation, 13, 481 .

Milnor, W. R. (1957). Electrocardiogram and vectorcardiogram in right ventricular hypertrophy and right bundlebranch block. Circulation, 16, 348.

Mulcahy, R. (1954). Mitral valvotomy during pregnancy. J. Irish med. Ass., 34, 96.

New York Heart Association (1939). Nomenclature and Criteria for Diagnosis of Diseases of the Heart, 4th ed., p. 72. New York. 